\title{
Multiple Regression Prediction Model for Cutting Forces in Turning Carbon-Reinforced PEEK CF30
}

\author{
Francisco Mata, ${ }^{1}$ Elena Beamud, ${ }^{1}$ Issam Hanafi, ${ }^{2}$ Abdellatif Khamlichi, ${ }^{2}$ Abdallah Jabbouri, ${ }^{3}$ \\ and Mohammed Bezzazi ${ }^{3}$ \\ ${ }^{1}$ Polytechnic School of Almadén, University of Castilla-La Mancha, Plaza Manuel Meca, 1, 13412 Almaden, Spain \\ ${ }^{2}$ Equipe de Modélisation et Simulation des Systèmes Mécanique (EM2SM), Faculty of Sciences at Tetouan, \\ BP. 2121, M'hannech, Tetouan, Morocco \\ ${ }^{3}$ Equipe de Recherche en Matériaux et Mécanique des Structures (EMMS), Faculty of Sciences and Technology at Tangier, \\ BP 416, Tangier, Morocco \\ Correspondence should be addressed to Francisco Mata, francisco.mcabrera@uclm.es
}

Received 20 April 2010; Accepted 21 July 2010

Academic Editor: J. W. Gillespie

Copyright () 2010 Francisco Mata et al. This is an open access article distributed under the Creative Commons Attribution License, which permits unrestricted use, distribution, and reproduction in any medium, provided the original work is properly cited.

\begin{abstract}
Among the thermoplastic polymers available, the reinforced polyetheretherketone with 30\% of carbon fibres (PEEK CF 30) demonstrates a particularly good combination of strength, rigidity, and hardness, which prove ideal for industrial applications. Considering these properties and potential areas of application, it is necessary to investigate the machining of PEEK CF30. In this study, response surface methodology was applied to predict the cutting forces in turning operations using TiN-coated cutting tools under dry conditions where the machining parameters are cutting speed ranges, feed rate, and depth of cut. For this study, the experiments have been conducted using full factorial design in the design of experiments (DOEs) on CNC turning machine. Based on statistical analysis, multiple quadratic regression model for cutting forces was derived with satisfactory $R^{2}$-squared correlation. This model proved to be highly preferment for predicting cutting forces.
\end{abstract}

\section{Introduction}

The machinability of composites in turning is studied in terms of tool wear, cutting forces, temperature, and surface quality. The addition of short fibres to thermoplastic composites enhances the properties such as stiffness, strength, and hardness and increases also the service temperature over unreinforced thermoplastics [1-5]. It has been reported that the addition of short fibers not only reduces the coefficient of friction and wear but also decreases the thermal expansion coefficient [6]. The carbon and glass fibres are the common reinforcements in thermoplastics because of low expansion rate and high flexural modulus. Park et al. developed heavy-duty hybrid carbon-phenolic hemispherical bearings. They used carbon-PEEK-phenolic hybrid composites with aluminum back up. They reported that the carbon fibre reinforcement provides maximum rigidity [7] the effects of PEEK powders and the bottom vent hole in the composite hemispherical bearing $(\mathrm{CHB})$ on the strength were exper- imentally investigated. Based on the investigation, a new $\mathrm{CHB}$ was fabricated by molding rather than machining the hemispherical surface to eliminate crack and delamination and tested in an experimental set-up; the experimental results showed that the new $\mathrm{CHB}$ outperformed the existing carbon PEEK CHB both in the endurance life and load bearing capacity [8] whereas the glass fiber reinforcement provides high temperature service [9]. As a result of these properties and potential applications, there is a need to understand the machining of unreinforced and reinforced polyetheretherketone (PEEK) composite materials.

Cutting forces are oscillating and periodic in nature when machining Fiber-Reinforced Plastics (FRPs). The oscillation originates from the repeated cutting tool encountering with the fibers and matrix phases, which produces drastically different magnitudes of cutting forces. The periodic nature of the cutting forces arises from the periodic changes of fiber orientation relative to the cutting speed vector as a result of the continuous turning of the work piece. The cutting 
forces generally increase with increasing the feed rate and the depth of cut. The dependence of cutting forces on cutting speed is not uniform across all different types of FRPs. The cutting force decreases with an increase in cutting speed when machining Glass Fiber-Reinforced Plastics (GFRP) and Carbon Fiber-Reinforced Plastics (CFRP), respectively. Further experimental studies in [10] supported these results and showed that the cutting speed only slightly affects the cutting forces when machining GFRP with different tool materials and geometries. However, it was shown in [11] that the cutting forces increase with an increase in cutting speed. The rate of change of the cutting forces with cutting speed is believed to be associated with the cutting temperatures. It has been described that the cutting forces for Polycrystalline diamond (PCD) are lower than those for Cemented Carbide (K15) when machining GFRP, especially at large feed rates, and that the cutting force is critically dependent on fiber orientation, as determined by the winding angle in filament wound tubes. The cutting force increases with increasing winding angle up to $15^{\circ}$ and decreases with further increase in winding angle. There are only a limited number of studies on effect of clearance angle on tool forces $[12,13]$. This work generally indicates that an increase in the clearance angle leads to slight decrease in the cutting force. It has been pointed that for a small depth of cut as compared to the nose radius, much of the material in the cutting edge path is pressed under the clearance face and then bounces back once the tool has passed [14]. Experimental results were used for modeling cutting forces using Response Surface Methodology (RSM) [15]. RSM is a combination of experimental, regression analysis and statistical inferences. RSM not only reduces the cost and time but also provides required information about the interaction effects with minimum number of experiments.

In order to develop the mathematical models based on experimental data, careful planning of the experimentation is essential. Hence, it is essential to have a well-designed set of experiments that can substantially reduce the number of experiments as compared to classical experimental design. In the present study, three parameters, namely, cutting speed, feed rate, and depth of cut are considered. The ranges of these parameters were selected based on preliminary investigations.

\section{Materials and Methods}

The work material used for the present investigation is reinforced PEEK composite with 30\% of fiber carbon (PEEK CF30) cylindrical work pieces with $50 \mathrm{~mm}$ in diameter and a length of $100 \mathrm{~mm}$. Dry turning experiments were carried out on a GORATU G CRONO 4 S CNC of $26.5 \mathrm{KW}$ spindle power and maximum spindle speed $3350 \mathrm{rpm}$ using TiNcoated cutting tools (Figure 1). Three component turning forces (radial force-Fp, cutting force-Fc, and feed force$\mathrm{Fa}$ ) were recorded with a Kistler piezoelectric dynamometer model 9121 connected to a load amplifier and data acquisition board, as shown in Figure 2. The mechanical and thermal properties of work material are summarized in Table 1.
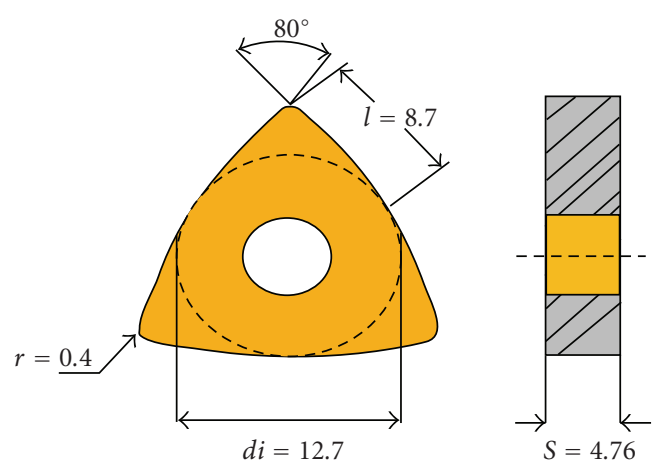

FIgURE 1: Cutting tool geometry.

Table 1: Properties of PEEK CF30.

\begin{tabular}{lcc}
\hline Mechanical and thermal properties & PEEK CF30 & Unit \\
\hline Tensile modulus & 7700 & $\mathrm{MPa}$ \\
Rockwell hardness & $\mathrm{M} 102$ & - \\
Charpy impact resistance & 35 & $\mathrm{KJ} / \mathrm{m}^{2}$ \\
Tensile strength & 130 & $\mathrm{MPa}$ \\
Melting temperature & 340 & ${ }^{\circ} \mathrm{C}$ \\
Density & 1.41 & $\mathrm{~g} / \mathrm{cm}^{3}$ \\
Coefficient of thermal expansion & $25 \times 10^{-6}$ & $\mathrm{~m} / \mathrm{m} / \mathrm{k}$ \\
at $\left(<150^{\circ} \mathrm{C}\right)$ & & \\
Coefficient of thermal expansion at & $55 \times 10^{-6}$ & $\mathrm{~m} / \mathrm{m} / \mathrm{k}$ \\
$\left(>150^{\circ} \mathrm{C}\right)$ & &
\end{tabular}

The aim of this study is to use statistical multiple regression method to derive predictive models for force components in machining of PEEK CF30. This consists in determining optimal correlation between the input variables (cutting speed, feed rate, and depth of cut) and the machining force components.

The derived model would be valuable in analyzing data relative to any given practical machining problem and to perform optimization of cutting conditions. Statistical regression-based models are known to provide pertinent estimates of magnitudes and to quantify statistical significance of the relationships between variables. Therefore, multiple regression analysis will be helpful to predict the criterion variables components of machining force (cutting force-Fc, radial force-Fp, and feed force-Fa) via the predictor variables that include cutting speed, feed rate, and depth of cut.

\section{Multiple Regression Prediction Models}

3.1. Formulation. Since the controllable machining parameters are the cutting speed, depth of cut, and feed rate, the proposed second order surface response model equation is taken under the following form:

$$
\begin{aligned}
Y= & \beta_{0}+\beta_{1} \mathbf{v}+\beta_{2} \mathbf{d}+\beta_{3} \mathbf{f}+\beta_{4} \mathbf{v} \cdot \mathbf{d}+\beta_{5} \mathbf{v} \cdot \mathbf{f} \\
& +\beta_{6} \mathbf{d} \cdot \mathbf{f}+\beta_{7} \mathbf{v}^{2}+\beta_{8} \mathbf{d}^{2}+\beta_{9} \mathbf{f}^{2},
\end{aligned}
$$




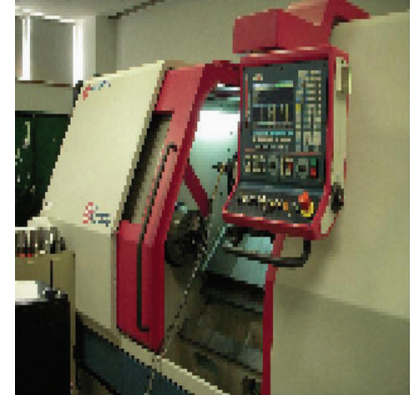

(a) CNC turning

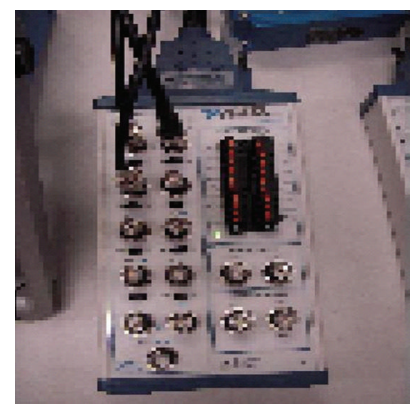

(d) Analog output multifunction data acquisition devices BNC-2110

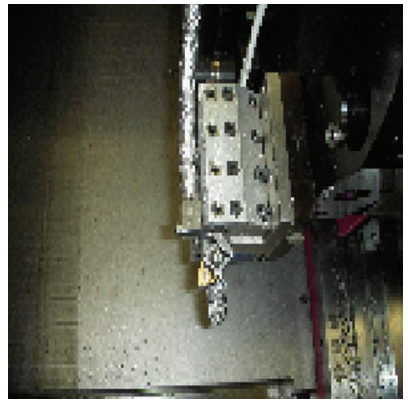

(b) Dynamometer

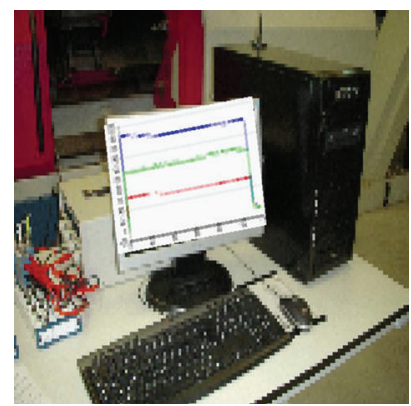

(e) Pc with software data acquisition

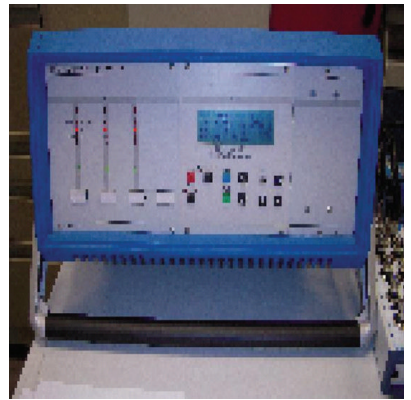

(c) Charge amplifier

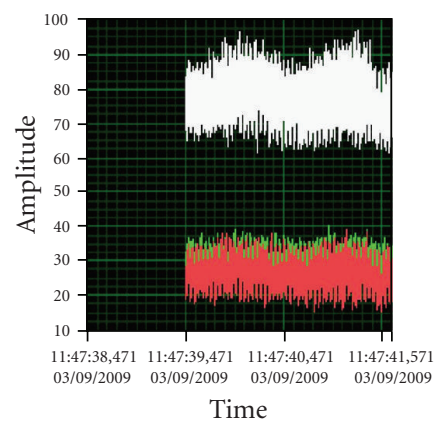

(f) A measurement record with periodic pulsation of the cutting forces

FIGURE 2: Details of the experimental set-up used for measurement of forces.

where, $Y$ is the estimated response and $\mathbf{v}, \mathbf{d}$, and $\mathbf{f}$ are the cutting speed, depth of cut, and feed rate.

This model can so be used to predict force components by mean of the coefficients $\beta_{0}, \beta_{1}, \ldots, \beta_{9}$. These coefficients are to be estimated by using

$$
B=\left(X^{t} X\right)^{-1} X^{t} Y,
$$

where $B$ is the matrix of parameter estimates, $X$ is the calculation matrix which includes linear, quadratic, and interaction terms, $X^{t}$ is the transpose of $X$, and $Y$ is the matrix of response.

To test the developed model, analysis of variance (ANOVA) is used to investigate and model the relationship between the response variable and the independent controllable variables. The form under which the response surface model is searched does not use any particular assumption regarding correlations between the intervening variables and takes all of them up to the second order. The prediction error of RSM-based mathematical models so developed is within $5 \%$ for all the materials tested as illustrated in Table 6 .

The accuracy of a mathematical model is given by

$$
\Delta=\frac{100}{n} \sum_{i=1}^{n}\left|\frac{y_{i, \exp t}-y_{i, \text { pred }}}{y_{i, \text { pred }}}\right|,
$$

where $y_{i, \exp t}$ is the experimental value of response corresponding to $i$ th trial, $y_{i \text {,pred }}$ is the RSM model predicted value of response corresponding to $i$ th trial, and $n$ is the number of trials.

The experiments were conducted according to full factorial design. The three cutting parameters selected for the
TABLE 2: Machining parameters and their levels.

\begin{tabular}{lcc}
\hline & level & code \\
\hline \multirow{2}{*}{ Cutting speed $(\mathrm{m} / \mathrm{min})$} & 300 & 1 \\
& 200 & 2 \\
& 100 & 3 \\
\hline \multirow{2}{*}{ Depth of cut $(\mathrm{mm})$} & 1.5 & 1 \\
& 0.75 & 2 \\
Feed rate $(\mathrm{mm} / \mathrm{rev})$ & 0.25 & 3 \\
& 0.20 & 1 \\
& 0.15 & 2 \\
& 0.10 & 3 \\
\hline
\end{tabular}

present investigation are cutting speed $(\mathbf{v})$, feed rate $(\mathbf{f})$, and depth of cut $(\mathbf{d})$. Since the considered variables are multilevel variables and their outcome effects are not linearly related, it has been decided to use three level tests for each factor. The machining parameters used and their levels are shown in Table 2.

An experimental layout plan based on full factorial design (FFD) of experiments has been selected. This consists of 27 experiments that are shown in Table 3.

\section{Results and Discussion}

The second order multiple regression model for the components of machining force is developed as a function of cutting parameters such as cutting speed $(\mathbf{v})$, feed rate (f), and depth of $\operatorname{cut}(\mathbf{d})$. 
From the experimental data, the regression equation was developed and is given as

$$
\begin{aligned}
\mathrm{Fp}= & 10.419+0.259 \mathbf{v}+76.987 \mathbf{d}+402.563 \mathbf{f} \\
& -0.001 \mathbf{v} \cdot \mathbf{d}-0.075 \mathbf{v} \cdot \mathbf{f}+57.076 \mathbf{d} \cdot \mathbf{f} \\
& -0.001 \mathbf{v}^{2}-28.228 \mathbf{d}^{2}-983.045 \mathbf{f}^{2} \\
F \mathrm{~F}= & -27.334+0.285 \mathbf{v}+88.970 \mathbf{d}+110.246 \mathbf{f} \\
& -0.140 \mathbf{v} \cdot \mathbf{d}-0.062 \mathbf{v} \cdot \mathbf{f}+136.076 \mathbf{d} \cdot \mathbf{f} \\
& -0.001 \mathbf{v}^{2}-3.590 \mathbf{d}^{2}-412.109 \mathbf{f}^{2} \\
\mathrm{Fa}= & -0.235+0.004 \mathbf{v}+29.745 \mathbf{d}+224.256 \mathbf{f} \\
& -0.038 \mathbf{v} \cdot \mathbf{d}+0.172 \mathbf{v} \cdot \mathbf{f}+220.013 \mathbf{d} \cdot \mathbf{f} \\
& -2.599 \mathbf{d}^{2}-825.238 \mathbf{f}^{2} .
\end{aligned}
$$

This analysis is carried out at a significance level of $5 \%$, that is, confidence level of $95 \%$. From the analysis of Table 4 it is evident that capabilities of the multiple regression-based models, $R^{2}$ factors, are higher than 0.90 . This shows that the second order models can explain the variation to the extent of $90 \%$. From Table 5 , it could be seen that $P$ values are less than .05 , hence the models are significant to $95 \%$ level of confidence. The prediction error of these models is within than $5 \%$ as illustrated in Table 6.

As shown in Figures 3, 4, and 5, the predicted values of radial force-Fp, cutting force-Fc, and feed force- $-\mathrm{Fa}$ as obtained from the models and the actual experimental data were efficiently in good agreement.

The influence of cutting parameters and their interaction effects can be analyzed by using 3D response graph. Figures $6(a)-6$ (c) show the 3D response graph for radial force; the response surface graphs are drawn by varying two parameters and keeping the other parameter at constant middle level.

Figure 6(a) shows the response graph for two varying parameters cutting speed and feed rate $(v * f)$ by keeping the third parameter depth of cut at constant middle level which indicates that the increase of cutting speed reduces the radial force. Figure 6(b) shows the surface plot for two varying parameters feed rate and depth of cut $(f *$ $d)$. The results show that the increases of the parameters increase the radial force. The relation between cutting speed with respect to depth of cut $(v * d)$ is presented in Figure 6(c). The increases of depth of cut increase the radial force.

Figures $7(\mathrm{a})-7$ (c) show the $3 \mathrm{D}$ response graph for cutting force. At minimal of the interaction parameters $(f * d)$ and $(v * d)$, we can observe that the cutting force is minimum.

Figures $8(\mathrm{a})-8(\mathrm{c})$ show the $3 \mathrm{D}$ response graph for feed force; Figure 8(a) indicates that the increase of cutting speed reduces the feed force. At minimal of the two interaction parameters $(f * d)$ and $(v * d)$, we can observe that the feed force is minimum.

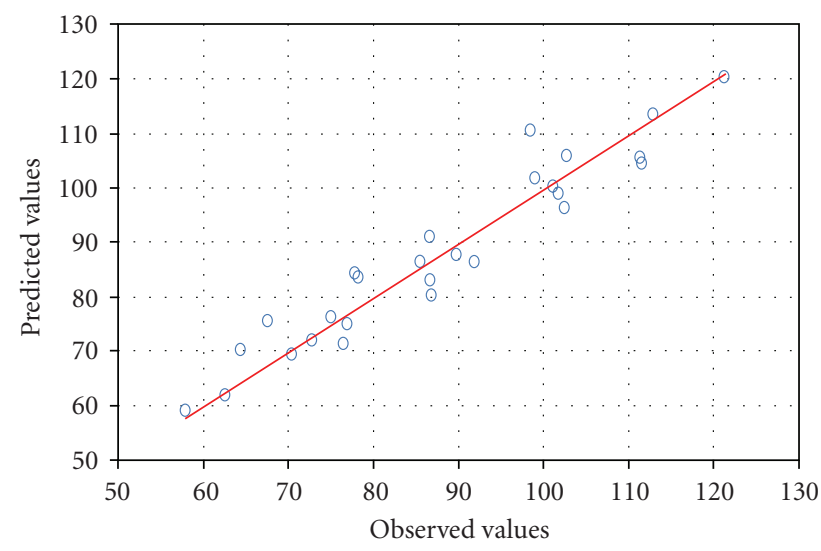

Figure 3: Design Expert Plot: predicted versus actual values plot for Radial force-Fp.

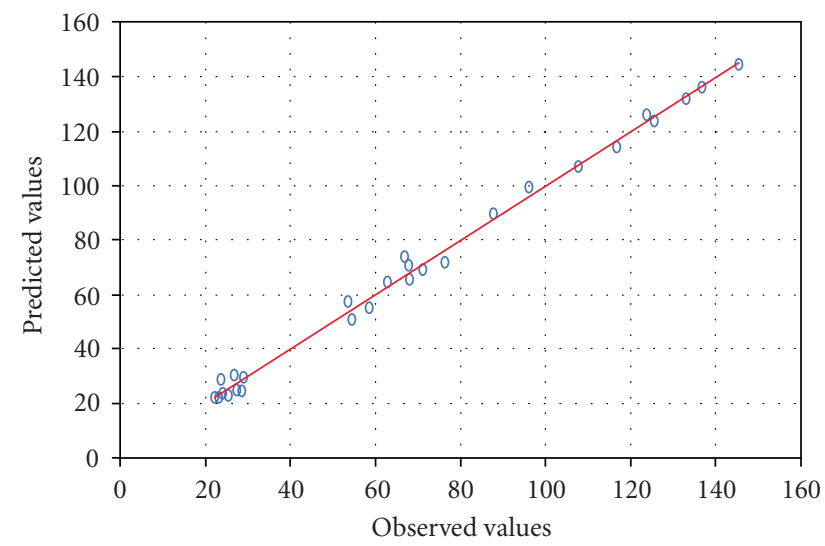

Figure 4: Design Expert Plot: predicted versus actual values plot for cutting force-Fc.

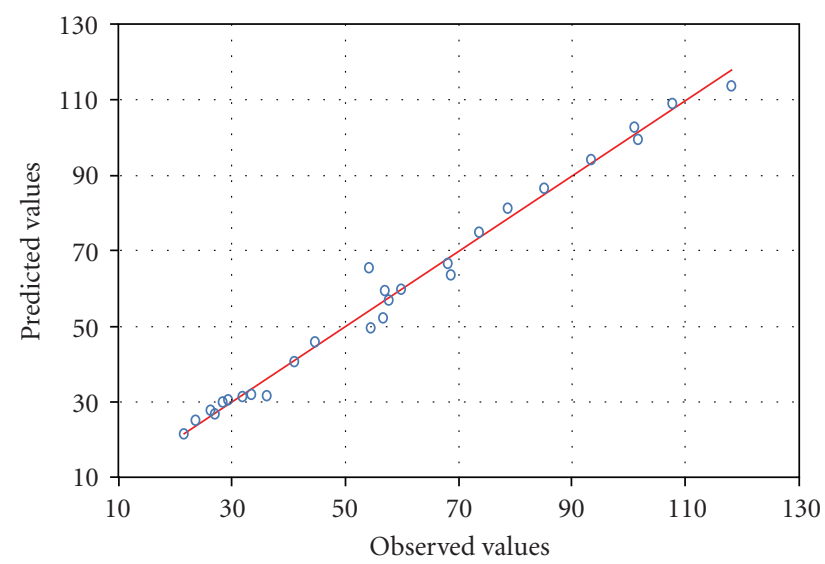

Figure 5: Design Expert Plot: predicted versus actual values plot for Feed force-Fa.

\section{Conclusion}

Using full factorial design in the design of experiment, the machining parameters which are influencing the radial force, 


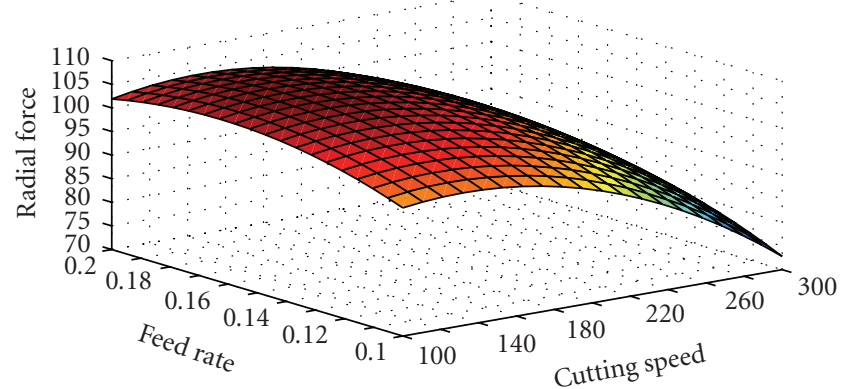

(a)

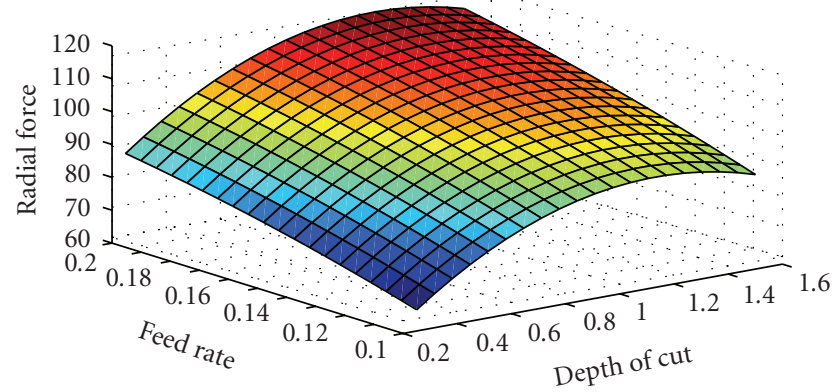

(b)

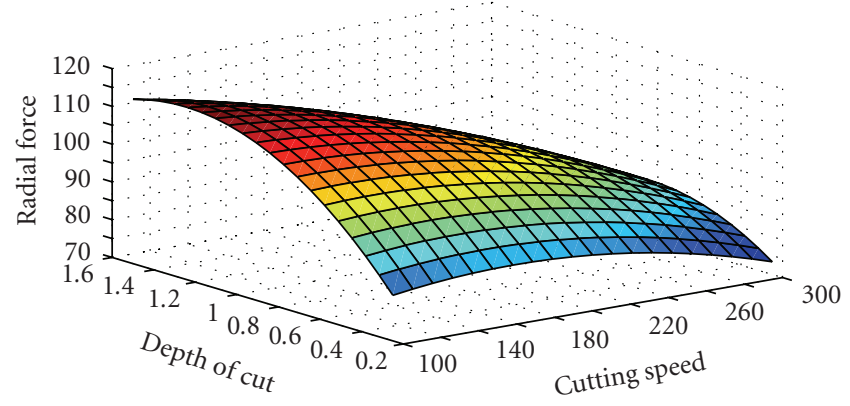

(c)

FIGURE 6: 3D response graphs for Radial force.

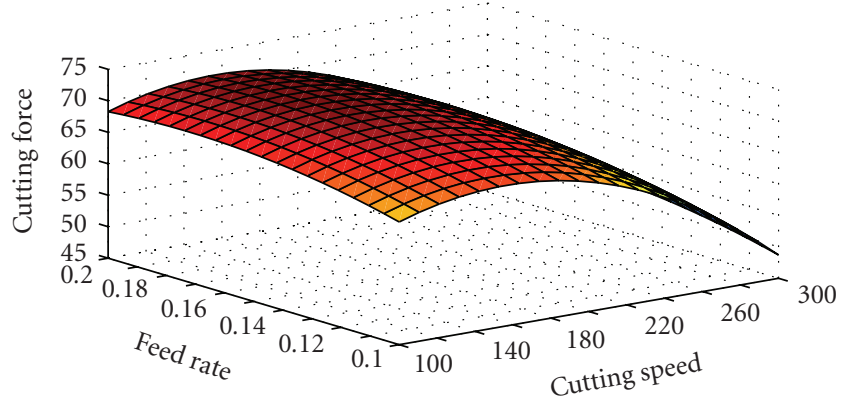

(a)

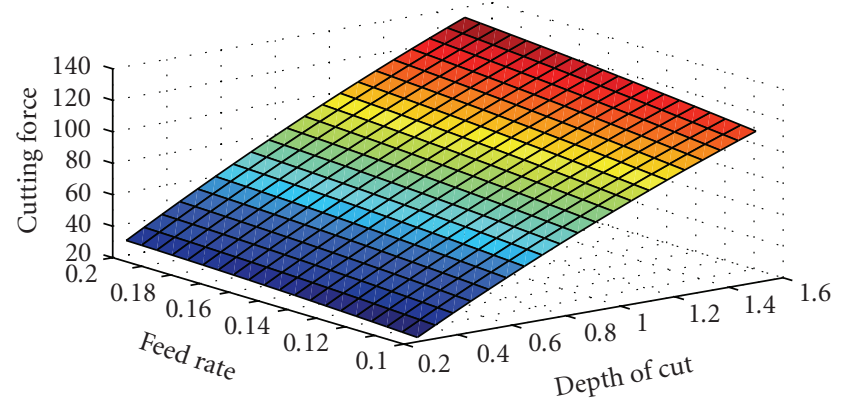

(b)

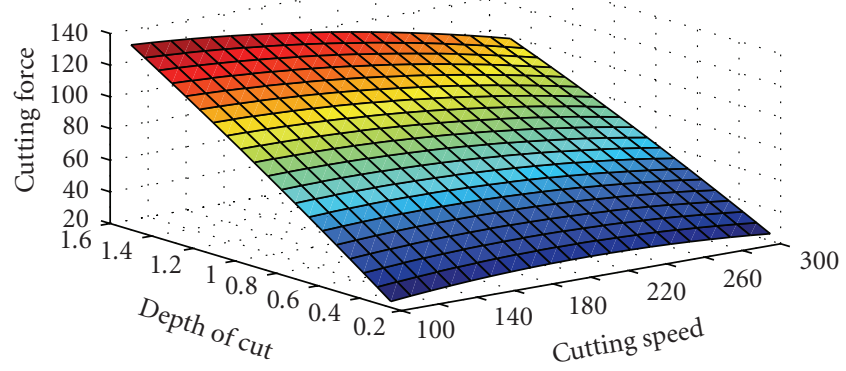

(c)

Figure 7: 3D response graphs for Cutting force. 


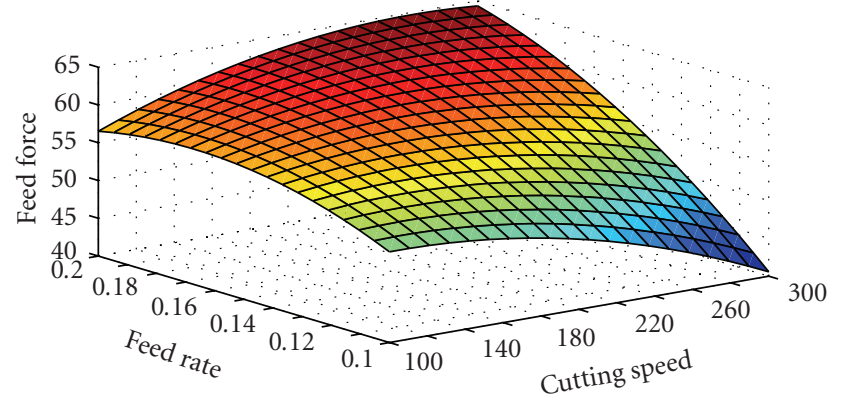

(a)

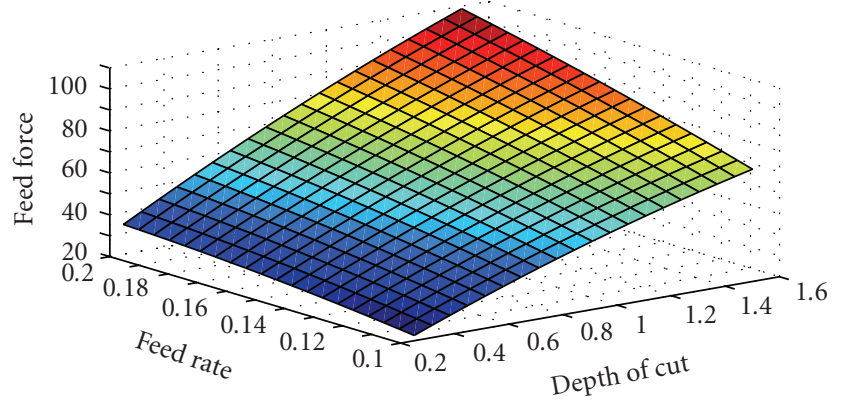

(b)

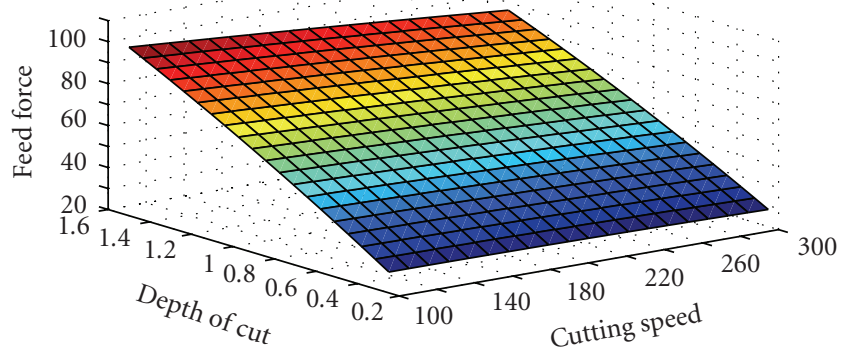

(c)

FIGURE 8: 3D response graphs for Feed force.

TABLE 3: Experimental lay out and results in terms of cutting forces.

\begin{tabular}{|c|c|c|c|c|c|}
\hline Cutting speed $\mathbf{v}$ & Depth of cut $\mathbf{d}$ & Feed rate $\mathbf{f}$ & Radial force Fp $(N)$ & Cutting force $\mathrm{Fc}(N)$ & Feed force $\mathrm{Fa}(N)$ \\
\hline 1 & 1 & 1 & 74.97 & 107.79 & 101.11 \\
\hline 1 & 1 & 2 & 64.31 & 96.00 & 85.13 \\
\hline 1 & 1 & 1 & 57.87 & 87.70 & 68.16 \\
\hline 1 & 2 & 1 & 77.80 & 53.46 & 59.94 \\
\hline 1 & 2 & 2 & 86.74 & 58.39 & 56.74 \\
\hline 1 & 2 & 1 & 76.44 & 54.36 & 41.10 \\
\hline 1 & 3 & 1 & 72.74 & 23.17 & 28.44 \\
\hline 1 & 3 & 2 & 70.33 & 23.89 & 26.22 \\
\hline 1 & 3 & 1 & 62.47 & 22.22 & 21.55 \\
\hline 2 & 1 & 1 & 111.18 & 133.03 & 107.79 \\
\hline 2 & 1 & 2 & 101.55 & 125.55 & 93.42 \\
\hline 2 & 1 & 1 & 89.62 & 116.70 & 73.67 \\
\hline 2 & 2 & 1 & 111.39 & 76.28 & 68.68 \\
\hline 2 & 2 & 2 & 100.93 & 70.93 & 57.69 \\
\hline 2 & 2 & 1 & 86.58 & 62.82 & 44.72 \\
\hline 2 & 3 & 1 & 85.42 & 28.75 & 33.57 \\
\hline 2 & 3 & 2 & 78.08 & 26.65 & 29.37 \\
\hline 2 & 3 & 1 & 67.52 & 23.65 & 23.61 \\
\hline 3 & 1 & 1 & 121.14 & 145.49 & 118.21 \\
\hline 3 & 1 & 2 & 112.73 & 136.84 & 101.71 \\
\hline 3 & 1 & 1 & 98.94 & 123.86 & 78.75 \\
\hline 3 & 2 & 1 & 98.43 & 66.91 & 54.20 \\
\hline 3 & 2 & 2 & 102.63 & 67.71 & 56.97 \\
\hline 3 & 2 & 1 & 102.39 & 67.94 & 54.59 \\
\hline 3 & 3 & 1 & 91.84 & 28.43 & 36.19 \\
\hline 3 & 3 & 2 & 86.60 & 27.19 & 31.93 \\
\hline 3 & 3 & 1 & 76.86 & 25.19 & 26.93 \\
\hline
\end{tabular}


TABLE 4: $R^{2}$ values for radial force, cutting force, and feed force models.

\begin{tabular}{lcccc}
\hline & Fp & Fc & \\
\hline Multiple regression coefficients $R^{2}$ & 0.92 & 0.99 & \\
\hline
\end{tabular}

TABLE 5: ANOVA of regression-based models for predicting cutting forces.

\begin{tabular}{|c|c|c|c|c|c|c|c|c|}
\hline & \multicolumn{2}{|c|}{ SS } & \multicolumn{2}{|c|}{ DF } & \multicolumn{2}{|c|}{ MS } & \multirow{2}{*}{$\mathrm{F}$} & \multirow{2}{*}{$\mathrm{P}$} \\
\hline & Model & Residual & Model & Residual & Model & Residual & & \\
\hline Radial force Fp & 6934.531 & 602.0132 & 9 & 17 & 770.5034 & 35.4125 & 21.7579 & 0.0000 \\
\hline Cutting force $\mathrm{Fc}$ & 43155.89 & 229.3698 & 9 & 17 & 4795.098 & 13.4923 & 355.3941 & 0.0000 \\
\hline Feed force $\mathrm{Fa}$ & 20896.93 & 280.0314 & 9 & 17 & 2321.881 & 16.4724 & 140.9556 & 0.0000 \\
\hline
\end{tabular}

TABle 6: Prediction error for all components of machining force.

\begin{tabular}{lccc}
\hline & Radial force & Cutting force & Feed force \\
\hline \% Prediction error & 4.3924 & 5.0879 & 4.3042 \\
\hline
\end{tabular}

cutting force, and feed force during machining of PEEK CF30 have been modeled using Multiple Regression. $R^{2}$ correlation coefficients for the quadratic models were quite satisfactorily as $0.9,0.99$, and 0.98 , respectively. Analysis of variance has shown high confidence levels of the obtained correlations. The experimental values agreed with the predicted results indicating suitability of the models. These state the adequacy of the derived models to obtain predictions for cutting forces within ranges of parameters that have been investigated during the experiments. In particular, the derived models could be used to optimize practical cutting conditions.

\section{References}

[1] F. Mata, V. N. Gaitonde, S. R. Karnik, and J. P. Davim, "Influence of cutting conditions on machinability aspects of PEEK, PEEK CF 30 and PEEK GF 30 composites using PCD tools," Journal of Materials Processing Technology, vol. 209, no. 4, pp. 1980-1987, 2009.

[2] J. P. Davim and F. Mata, "Chemical vapour deposition (CVD) diamond coated tools performance in machining of PEEK composites," Materials and Design, vol. 29, no. 8, pp. 15681574, 2008.

[3] J. P. Davim and F. Mata, "New machinability study of glass fibre reinforced plastics using polycrystalline diamond and cemented carbide (K15) tools," Materials and Design, vol. 28, no. 3, pp. 1050-1054, 2007.

[4] J. P. Davim, P. Reis, V. Lapa, and C. Conceiçao António, "Machinability study on polyetheretherketone (PEEK) unreinforced and reinforced (GF30) for applications in structural components," Composite Structures, vol. 62, no. 1, pp. 67-73, 2003.

[5] J. P. Davim and P. Reis, "Machinability study on composite (polyetheretherketone reinforced with 30\% glass fibre-PEEK GF 30) using polycrystalline diamond (PCD) and cemented carbide (K20) tools," International Journal of Advanced Manufacturing Technology, vol. 23, no. 5-6, pp. 412-418, 2004.

[6] B. Bharat, Principles and Applications of Tribology, John Wiley \& Sons, New York, NY, USA, 1999.
[7] D. C. Park, S. M. Lee, B. C. Kim, H. S. Kim, and D. G. Lee, "Development of heavy duty hybrid carbon-phenolic hemispherical bearings," Composite Structures, vol. 73, no. 1, pp. 88-98, 2006.

[8] S. M. Lee, D. C. Park, B. C. Kim, and D. G. Lee, "Strength of functionally gradient composite hemispherical bearings," Composite Structures, vol. 74, no. 2, pp. 145-152, 2006.

[9] A. P. Harsha and U. S. Tewari, "Two-body and three-body abrasive wear behaviour of polyaryletherketone composites," Polymer Testing, vol. 22, no. 4, pp. 403-418, 2003.

[10] T. Kaneeda, "CFRP cutting mechanism," Transaction of North American Manufacturing Research Institute of SME, vol. 19, pp. 216-221, 1991.

[11] M. Alauddin, I. A. Choudhury, M. A. El Baradie, and M. S. J. Hashmi, "Plastics and their machining: a review," Journal of Materials Processing Technology, vol. 54, no. 1-4, pp. 40-46, 1995.

[12] A. Koplev, AA. Lystrup, and T. Vorm, "The cutting process, chips, and cutting forces in machining CFRP," Composites, vol. 14, no. 4, pp. 371-376, 1983.

[13] D. H. Wang, M. Ramulu, and D. Arola, "Orthogonal cutting mechanisms of graphite/epoxy composite-part I: unidirectional laminate," International Journal of Machine Tools and Manufacture, vol. 35, no. 12, pp. 1623-1638, 1995.

[14] X. M. Wang and L. C. Zhang, "An experimental investigation into the orthogonal cutting of unidirectional fibre reinforced plastics," International Journal of Machine Tools and Manufacture, vol. 43, no. 10, pp. 1015-1022, 2003.

[15] D. C. Montgomery, Design and Analysis of Experiments, John Wiley \& Sons, New York, NY, USA, 2001. 

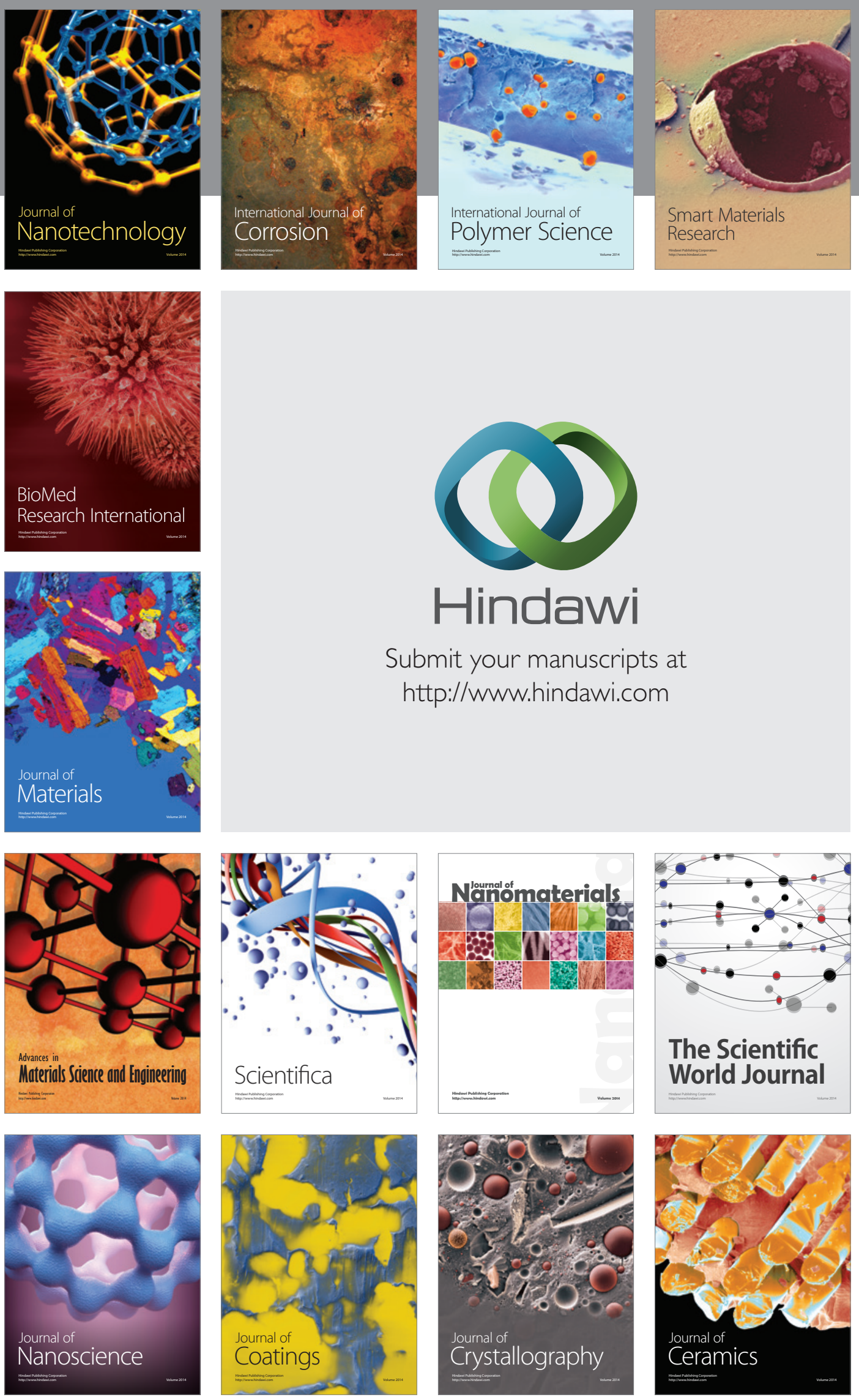

The Scientific World Journal

Submit your manuscripts at

http://www.hindawi.com

\section{World Journal}

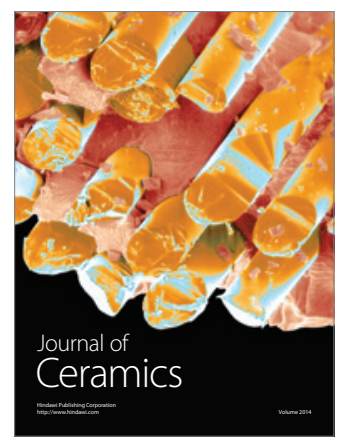

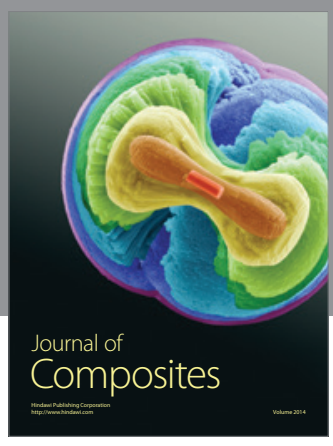
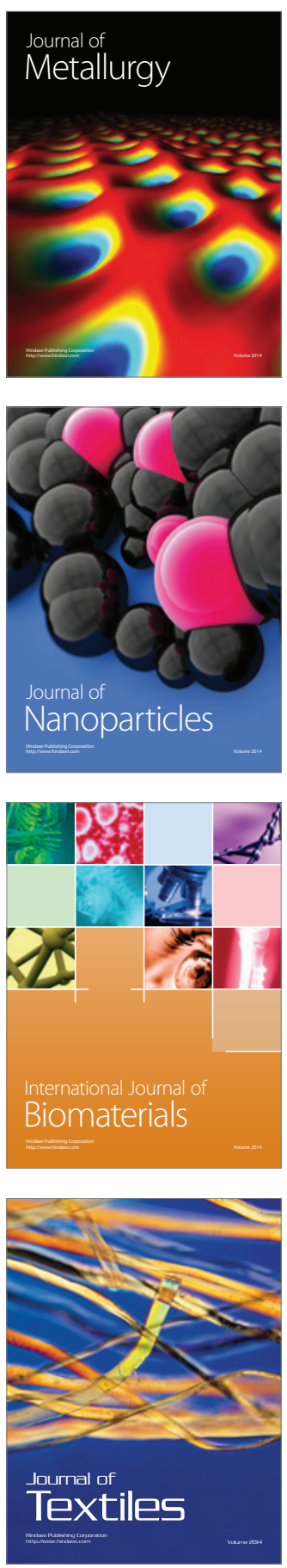